\begin{tabular}{|c|l|}
\hline Title & The Unlearning of Managerial Skills : A Qualitative Study of Executive Officers \\
\hline Author(s) & Matsuo, Makoto \\
\hline Citation & $\begin{array}{l}\text { European Management Review,16, 303 315 } \\
\text { https://doi.org/10.1111/emre.12122 }\end{array}$ \\
\hline Issue Date & 2019 \\
\hline Doc URL & http://hdl.handle.net/2115/74861 \\
\hline Type & article (author version) \\
\hline File Information & Self-archiving (EMR2019).pdf \\
\hline
\end{tabular}

Instructions for use 
DOI: $10.1111 /$ emre.12122

\title{
The Unlearning of Managerial Skills: A Qualitative Study of Executive Officers
}

\author{
MAKOTO MATSUO ${ }^{1}$ \\ Graduate School of Economics and Business Administration, Hokkaido University, Sapporo, \\ Japan
}

\begin{abstract}
Although the abilities of executive officers to unlearn may have a significant impact on organizational unlearning, few studies have investigated the individual unlearning transition. The goal of this study was to examine the managerial unlearning process upon promotion from senior manager to executive officer, based on the upper echelons perspective and leadership pipeline model. Analyses of interview data with 46 executive officers at medium and large-sized Japanese firms indicated that they unlearned and learned their managerial skills in relation to 'decision making', 'delegation and motivation', and 'collecting information', and that the unlearning process was discontinuous. Specifically, decision making skills were switched from 'short-term, analytic, and partial' to 'long-term, intuitive, and holistic'. Skills in delegation and motivation were transformed from 'directive' to 'dedicated and entrusting'. Skills in collecting information were switched from 'direct collection' to 'network-based collection'. This study contributes to the literature on managerial skills by showing empirically the discontinuous nature of management transitions with regard to an unlearning perspective.
\end{abstract}

Keywords: unlearning; managerial skills; executive officer; leadership pipeline model; upper echelons

\section{Introduction}

As successful experiences are accumulated over the years, organizations emphasize efficiency, grow complacent, and learn too little (Nystrom and Starbuck, 1984). To survive in an increasingly turbulent environment, organizations need to 'unlearn', or discard old knowledge or routines to make way for new ones in certain industries (Hedberg, 1981; Tsang, 2008). Thus, unlearning or forgetting is an important step for enhancing generative learning and innovation (Fernandez et al., 2012). It should be noted, however, that individual unlearning is necessary for unlearning at the organizational level, because organizations ultimately learn via their members (Kim, 1993). In particular, unlearning is imperative for top executives because they influence organizational performance through their values, personalities, behaviors, and the strategic choices they make, as suggested by the upper echelons perspective (Hambrick and Mason, 1984; Hambrick, 2007). That is, the success of organizational unlearning depends on the top management team because enacting such changes requires decision making authority (Hutzschenreuter et al., 2012).

\footnotetext{
${ }^{1}$ Correspondence: Makoto Matsuo, Graduate School of Economics and Business Administration, Hokkaido University, Kita9 Nishi7,Kita-ku, Sapporo, Hokkaido, Japan, Tel/Fax: +81-11-706-4065. E-mail: mmatsuo@econ.hokudai.ac.jp
} 
Despite its importance, the individual unlearning process, especially in the upper echelons, has been neglected in previous studies (Klein, 1989; Hislop et al., 2014). Past research on executive managers' capabilities have identified necessary skills and capabilities for their positions (e.g., Adner and Helfat, 2003; Kor and Mesko, 2013; Helfeat and Peteraf, 2015). However, little research has investigated the transition in managerial skills from senior managers to executive directors, during which they are required to transform their skills substantially, because executive directors typically need to handle multiple businesses (Charan et al., 2001). Although several models of managerial skills and capabilities have been proposed (Katz, 1955; Mintzberg, 1973; Adner and Helfat, 2003), differences in managerial skills between senior management and executive levels have not been examined sufficiently. The purpose of this study was to investigate the unlearning process of managers by comparing their managerial skills before and after their promotions to executive positions, using interview data with male managers at medium and large-sized Japanese firms.

This paper makes two contributions to the literature. First, this study identified the types of managerial skills that upper-echelon managers should unlearn when they are promoted from senior management to executive positions. Second, the present research found discontinuous transitions in managerial skills before and after promotions to executive positions. By investigating the transition flow, it may be possible to gain insights into the processes of individual unlearning that occur in the upper echelons of an organization (Hambrick and Mason, 1984; Hambrick, 2007).

The paper is organized as follows. First, the literature on unlearning, management transition, and managerial skills is reviewed. Next, a research question is proposed based on the literature review. Then, the mixed method, which combines qualitative content analysis with the groundedtheory approach to interview data obtained from executive officers, is presented. Finally, the results are presented and discussed from theoretical and practical perspectives.

\section{Theoretical Background}

Unlearning at organizational and individual levels

Organizational unlearning is viewed as the changing of beliefs, norms, values, procedures, and routines to make way for new ones in organizations (Akgun et al., 2006; Tsang and Zahra, 2008). Hedberg (1981) argued that discarding obsolete knowledge is critical for gaining new knowledge, and the lack of ability to engage in unlearning is a crucial weakness of many organizations. The idea behind unlearning is that the inability to forget may become a major hindrance to further learning or innovation (Easterby-Smith et al., 2004; Fernandez et al., 2012). According to Akgun et al. (2007), cognitive psychology has conceptualized unlearning as changes in belief structure or mental model that help bring about acceptance of new knowledge, whereas verbal learning psychology has viewed unlearning as deleting and replacing old stimuli by interpolated learning. Thus, learning is a process that can include unlearning (Haeffner et al., 2012). Antal and Kocka (2008) stated that Hedberg's (1981) concept of unlearning remained a central element of organizational learning theory.

As firms must disorganize some part of their knowledge store to unlearn, similar disorganization must also take place at the individual level (Rebernik and Sirec, 2007). We should pay attention not only to organizational unlearning but also to individual unlearning, because learning and unlearning takes place at both levels (Rebernik and Sirec, 2007) and they interact one another. Zhao et al. (2013) argued that the process of organizational unlearning is the 
evolution of individual unlearning, group unlearning, and organizational unlearning. That is, individual unlearning promotes group unlearning, which eventually results in organizational unlearning. In particular, top managers play crucial roles in the process of organizational unlearning (Zhao et al., 2013). For example, if CEOs or executive managers change their management styles or strategic beliefs, there will be changes in organizational routines such as performance appraisal systems, organizational structure, and production systems. All of them may have impacts on the learning and unlearning of middle managers and staff employees.

Previous researchers defined individual unlearning as the process by which individuals consciously choose to give up, abandon, or stop using knowledge, values, or behaviors to acquire new ones (Becker, 2005; Tsang and Zahra, 2008; Hislop et al., 2014). The definition involves three assumptions on individual unlearning. First, individual unlearning is a conscious and intentional process of abandoning knowledge, values, or behaviors. Second, what is unlearned is not permanently lost or destroyed, but it is not used (Hislop et al., 2014). Then, individual unlearning is distinguished from individual forgetting which refers to unconscious or accidental giving up of something (Hislop et al., 2014). This implies that individuals who have unlearned keep the old knowledge or a repertoire of behaviors in their memory, which can be made use of if necessary. Third, abandoning existing knowledge, values, or behaviors occurs simultaneously with acquiring new ones (Becker, 2005). That is, unlearning may occur when the individual becomes aware that knowledge, values, or behaviors he or she possesses are no longer valid or useful and needs to acquire new ones. Of the three assumptions, the second is not applicable to the definition of organizational unlearning, because old routines are usually replaced by new routines in the organization.

Importantly, unlearning is not an identical concept to learning; instead, unlearning is a key step within learning. There may be three types of learning (Table 1). First, an individual acquires knowledge and skills without abandoning old ones. He/she simply adds new things to the repertoire of knowledge and skills, and makes use of them as required. This can be termed 'accumulative learning', which may be closely related to a manager's exploitation activities, including improving and extending existing competences (March, 1991; Mom et al., 2007). Second, an individual abandons or discards old knowledge to acquire new material. This can be labeled 'updating or replacing learning', which may be closely associated with a manager's exploration activities, including experimenting with new approaches and reconsidering existing beliefs (Mom et al., 2007). Prior studies on unlearning have stressed the importance of updating or replacing knowledge to keep pace with ongoing changes (e.g., Starbuck, 2016; Cepeda-Carrión et al., 2015). The third type is 'focusing or selective learning', in which an individual just

Table 1 Unlearning and learning types

\begin{tabular}{cccc}
\hline & \multicolumn{3}{c}{ Learning types } \\
\cline { 2 - 4 } Learning behaviors & Accumulative & Updating or replacing & Focusing or selective \\
\hline $\begin{array}{c}\text { Acquiring knowledge and skills } \\
\text { Abandoning knowledge and skills } \\
\text { (Unlearning) }\end{array}$ & + & + & - \\
\hline
\end{tabular}

Note: '+' = commit; '-' = not commit. 
abandons or no longer uses obsolete or outdated knowledge, and focuses on existing effective knowledge, without acquiring a new one. This may happen when an individual has several repertoires of knowledge and skills, and is able to select necessary one(s). Among these three types of learning, it is problematic that executive officers typically remain in the first type of learning, adopting no-longer-appropriate managerial skills that they used in lower-ranking positions (Charan et al., 2001). As such, they would do better to adopt the second type of learning, which includes unlearning, after being newly promoted to higher positions, and facing new challenges.

The upper echelon perspective assumes that top executives influence organizational performance through their personal characteristics and behaviors (Hambrick and Mason, 1984; Hambrick, 2007; Sosik et al., 2010), and that top management teams collectively possess the skills that affect their performance (Coad and Timmermans, 2014). Thus, the abilities of executive officers to unlearn may have a major impact on organizational unlearning, because these individuals have decision making authority to enact and acknowledge changes in organizational routines (Hutzschenreuter et al., 2012). Changes in managers' frames of reference and mental models can spur exploration that enriches innovation (Zahra et al., 2011). Vera and Crossan (2004) argued that this mode of leadership on the part of CEO and executive officers promotes learning that challenges institutionalized learning. Despite the importance of the executive officers' unlearning, there are few theories confirmed by empirical evidence that identify how executive managers unlearn and what factors may influence such unlearning.

\section{Pipeline model and management transition}

The leadership pipeline model proposed by Charan et al. (2001) suggests that executive officers need to unlearn, especially after being promoted from senior manager positions. This model assumes that there are six leadership transitions, or passages, in large organizations: from managing self to managing others (passage 1); from managing others to managing managers (passage 2); from managing managers to functional manager (passage 3); from functional manager to business manager (passage 4); from business manager to group manager (passage 5); and from group manager to enterprise manager (passage 6). The leadership pipeline model has some support in academic literature (Kaiser, 2011).

Charan et al. (2001) stated that each passage requires managers to acquire a new way of managing and leading and to leave old ways behind. As this study focused on the learning processes of executive managers, passages 5 and 6 are described here briefly, based on Charan et al. (2001). At passage 5, when a manager is promoted from business manager to group (executive) manager, he or she has to be aware of valuing the success of other people and helping their people and businesses to succeed. If a group manager does not value the success of others, he or she may fail to inspire and support the performance of the business managers who report to him or her. A group manager also needs to help the development of business managers using coaching skills. During the sixth passage, there is a subtle but fundamental shift in his/her responsibilities, from strategic to visionary thinking, and from an operations perspective to a global one. This is why the present research focused on the unlearning of managerial skills during this passage. The new leadership role requires managers to have well-developed external sensitivities including managing external constituencies, sensing significant external shift, and doing something about such insights proactively. To negotiate any career crossroad effectively, managers-in-transition must decide which elements in their previous role they should omit or minimize, preserve or continue to use, and supplement or do more or better (Freedman, 2011). Although the roles of 
new positions require managers to transform, upgrade, and refine their skills, most of them, due largely to instinct, tend to stick with previous, but no-longer-appropriate, skills.

Reviewing the literature on management transition, Meuse et al. (2011) pointed out that there are two perspectives: the continuous versus the discontinuous. The continuous or continuity perspective posits that all levels of effective leaders need to possess the same behavioral repertoire, and that promotion requires managers to perform more of those behaviors. Conceivably, an assumption may be established that managerial skills used at the level of lower positions can be applicable to the tasks of higher positions, and that managers need to periodically brush up their skills when they are promoted. In contrast, the discontinuity perspective suggests that leadership behavior positively related to effectiveness at a lower level may become negatively related to effectiveness at higher levels. Thus, managers need to stop performing those behaviors that are not contributing to effectiveness after being promoted (Meuse et al., 2011). Obviously, the leadership pipeline model proposed by Charan et al. (2001) adopts the discontinuity perspective of management transition.

Based on an empirical study, Kaiser and Craig (2011) found that managerial behaviors associated with effectiveness were different at the bottom, middle, and top and that these differences were often discontinuous, reflecting qualitative differences by level. Specifically, results suggest that middle manager effectiveness is a function of more directive and less empowering leadership, whereas executive effectiveness is characterized by more empowering and less directive leadership. The results correspond to the leadership pipeline model and discontinuity perspective of management transition. Similarly, Dai et al. (2011) reported that when managers move to different position levels in an organization, the requirement for successful job performance changes. The results support the pipeline model, suggesting that managers must unlearn obsolete skills and learn new ones to be effective in new positions. However, the comprehensiveness of such transitions has not been looked at thoroughly and extensively. Specifically, previous studies have only focused on interpersonal skills. Therefore, further investigations are necessary to comprehend cognitive and decision making perspectives.

\section{Managerial skills of executive officers}

Descriptions of managerial role requirements have a long history (Dierdorff et al., 2009). There are two traditional models that have been often cited in research on managerial roles or skills. One is Katz's (1955) model of managerial skills, and the other is Mintzberg's $(1971,1973)$ model of managerial roles. Recently, research on a newer model, 'dynamic managerial capabilities' (Adner and Helfat, 2003), has attracted attention in the strategic management literature. These three models are reviewed here.

Katz (1955) classified managerial skills into technical, human, and conceptual skills. Technical skill implies proficiency in a specific kind of activity, involving methods, processes, procedures, or techniques. Human skill is the ability to work effectively as a group member and to build cooperative effort within the team he or she leads. Conceptual skill involves the ability to recognize how the various functions of the organization depend on one another, and how changes in any one part affect the others. Katz (1955) argued that conceptual skill becomes increasingly critical in more responsible executive positions.

Based on a literature review, Dierdorff et al. (2009) suggested that there are three general categories of managerial work role requirements: technical/administrative; interpersonal; and conceptual requirements, which are in accordance with Katz's (1955) model. Technical/administrative requirements involve managerial work dealing with the traditional 
functions of business. Interpersonal requirements include interacting, influencing, and leading others. Conceptual requirements involve knowledge, skills, characteristics, and behaviors associated with cognitive processes. Dierdorff et al. (2009) argued that although technical/administrative, interpersonal, and conceptual requirements appear to broadly underlie all managerial work, these managerial role requirements are likely to vary across different managerial occupations with regard to their relative significance to role enactment.

In contrast, Mintzberg $(1971,1973)$ proposed a different model of managerial roles based on research that considered the chief executives of five medium to large organizations. He classified the manager's role into interpersonal, informational, and decisional roles, which can be further divided into ten distinct roles. The interpersonal roles include three roles involving interpersonal contact: 'figurehead' (performing a number of ceremonial, legal, and social duties as a symbolic head); 'leader' (motivating, encouraging, and training employees); and 'liaison' (establishing a network of contacts to bring information and favors to the organization).

The informational role encapsulates three roles relating to the processing of information: 'monitor' (receiving internal and external information with a view to understanding the organization and environment); 'disseminator' (transmitting information received from outsiders or from other subordinates to members of the organization); and 'spokesperson' (transmitting information to outsiders on the organization's performance, policy, and plan).

The decisional role includes four roles relating to the organization's important actions: 'entrepreneur' (being an initiator and designer of much of the controlled change in the organization); 'disturbance handler' (handling important, unexpected disturbances that the organization faces); 'resource allocator' (allocating organizational resources of all kinds for significant organizational decisions); and 'negotiator' (participating in important negotiation sessions). The replicating studies have provided some support for Mintzberg's (1973) model (e.g., Pavett and Lau, 1983, 1985; Martinko and Gardner, 1990), and it has been used as an important source of reference that has informed management research and education (Gibbs, 1994; Tengblad, 2006).

More recently, Adner and Helfat (2003) introduced a model of dynamic managerial capabilities, or a manager's capacity to build, integrate, and reconfigure organizational resources and competencies. This concept is built on work on 'dynamic capabilities' (e.g., Teece et al., 1997), and assumes that management intent, in the upper echelons, influences organizational outcomes (Martin, 2011). Specifically, the capabilities focus on managers' resource-related decisions (Sirmon and Hitt, 2009), including managerial human capital, managerial social capital, and managerial cognition (Adner and Helfat, 2003). 'Managerial human capital' refers to learned skills and knowledge that managers develop through their work experience, training, and education, whereas 'managerial social capital' consists of goodwill derived from formal and informal relationships with others (Helfat andMartin, 2015). 'Managerial cognition' includes managerial beliefs and mental models that serve as a basis for a manager's decision making. Previous empirical studies indicate that the dimensions of dynamic managerial capabilities affect firm performance and strategic change (Helfat and Martin, 2015; Sirmon and Hitt, 2009). Kor and Mesko (2013) stated that the CEO influences the absorptive capacity of the executive team in achieving an evolutionary fit, through the configuration and orchestration of senior executive dynamic capabilities.

Comparing these three models, conceptual skills (Katz, 1955), decisional roles (Mintzberg, 1973), and managerial cognition (Adner and Helfat, 2003) are similar and closely related. However, as each model has its own unique configuration of these dimensions, there is no 
consensus as to which model is the most appropriate for upper-echelon managers. Additionally, the models, except for the Katz (1955) model, do not adopt a discontinuity perspective, which postulates that managerial jobs change dramatically as managers ascend the hierarchy.

\section{Research question}

Unlearning has been investigated mainly as an organizational level concept, while the individual unlearning process has been neglected in previous studies (Hislop et al., 2014). In particular, the unlearning of individual executive officers is significant for firms because it may have an influence on unlearning at the organizational level (Hutzschenreuter et al., 2012). According to discontinuous perspectives of management transition (Charan et al., 2001; Meuse et al., 2011), executive officers have to unlearn their managerial skills when being promoted from senior management. However, existing models of managerial skills and capabilities do not assume transitions in managerial skills before and after promotions to executive positions. Additionally, the appropriate configuration of managerial skills for the upper echelon remains unclear. Thus, the following research question was proposed:

Research question: What managerial skills do managers abandon and acquire when they are promoted from senior manager positions to executive officers?

The main difference between a senior manager and an executive officer is that the former handles a single business while the latter is in charge of multiple businesses. Charan et al. (2001) stated that executive officers who handle multiple businesses need to prepare themselves for bigger decisions, and greater risks and uncertainties. The transition in managerial responsibility may require executive officers to unlearn previously acquired skills. In the analysis, this paper focused on facts associated with managerial skills or capabilities rather than values.

\section{Methods}

\section{Research strategy}

The methodological approach adopted by this study was characterized by the following three features. First, the author analyzed interview data collected by senior managers as interviewers. The senior managers were asked to find a high-performing executive officer in their firms, and interview him or her. An advantage of this method is that the interviewers occupied senior positions and therefore had the opportunity to identify closely and communicate with high-level executive officers, who were successful in unlearning their knowledge and skills. That is, the interviewers were able to observe and assess how true interviewees' comments were, and how well their management skills had worked in their executive positions. Second, the interview data were analyzed primarily using qualitative content analysis, which has been used to transform interview transcripts into categories (Molina-Azorin, 2012). Third, the three-step coding procedure proposed by the grounded-theory approach (Strauss and Corbin, 1998) was adopted for developing and integrating the categories related to the unlearning of executive officers, because the content analysis is considered to be limited with regard to its theoretical underpinnings (Hsieh and Shannon, 2005).

\section{Data collection}

The research was carried out in 46 medium and large-sized Japanese firms in various industries. 
The interviewers were senior managers of the firms who participated in a management training program in which the author was a lecturer. The main goal of the program was to develop the leadership skills of the participants, who were candidates for CEOs of their firms.

In the program, the author asked the senior managers to conduct interviews with excellent executive officers they considered as role models, and to submit interview reports. There are two reasons why this approach was adopted. First, most of the senior managers had maintained good relationships with the interviewees, allowing them to extract frank opinions throughout the interviews. In particular, Japanese managers, in general, like to convey their past experiences to their subordinates. This suggested that more substantial interviews would be possible when the interviewers were internal managers instead of external researchers. The second reason is that as the senior managers were CEO candidates, they had networks and capabilities for identifying and selecting excellent executive officers within their organizations.

The main question in the interview was, 'What managerial skills should be changed, revised, or discontinued when you are promoted from senior manager to executive officer?' Interviewers were asked to conduct semi-structured interviews based on this question for more than an hour, and to write down the comments of interviewees as field notes as accurately as possible. The interviewers had received training on field work including interview methods by professional scholars and had conducted several field work initiatives in the management training course. In the interview, they were asked to describe interviewees' concrete and precise comments in the field notes, and to submit interview reports based on the field notes. The interviews were not taperecorded because of the fact that might hinder an open conversation between interviewers and interviewees. However, interviewers were encouraged to record interviewees' remarks and voices in a realistic manner in their reports.

All of the executive officers were men. Most of the organizations the 46 interviewees belonged to were top level companies in a variety of industries. Table 2 shows the characteristics of the companies and interviewees. They worked for manufacturing concerns, including electronics (8), machine (5), food (3), automotive (2), chemicals (2), pharmaceuticals (2), commodities (2), others (2) (56.5\%), and non-manufacturing firms, including IT/communications (6), transportation (6), construction (4), insurance (2), and trading (2) (43.5\%). Regarding numbers of employees, $8.7 \%$ had 999 or fewer, $6.3 \%$ had 1,000-4,999, 38.2\% had 5,000-9,999, and $46.8 \%$ had 10,000 or more. Interviewees' ages ranged from 50 to 65 years old.

\section{Analysis}

This study adopted mixed-methods research, or the collection and analysis of both quantitative and qualitative data in a single study in which the data were collected concurrently or sequentially (Creswell et al., 2003). Mixed-methods research is one of the three major research paradigms, along with quantitative and qualitative research (Johnson et al., 2007). In the present study, interview data were analyzed using primarily a grounded-theory approach (Glaser and Strauss, 1967; Strauss and Corbin, 1990, 1998). Then, content analysis (Babbie, 2001) was used to supplement the results. This method has been labeled 'qualitative-dominant mixed-methods research' (Johnson et al., 2007).

First, to extract categories of managerial skills unlearned, the interview data in the reports were analyzed using a grounded theory approach (Glaser and Strauss, 1967; Strauss and Corbin, 1990, 1998). A grounded theory approach was adopted because it is a qualitative research method for developing an inductively derived grounded theory about a phenomenon (Strauss and Corbin, 1998), and it can be applied not only to sociological research but also to psychological research 
(Henwood and Pidgeon, 1995; Rennie et al., 1998). According to Strauss and Corbin (1990), the elements of grounded theory are concepts, categories and propositions. Concepts are the basic unit of analysis, emerging from the conceptualization of actual data; categories are higher in level and more abstract than the concepts. Propositions indicate generalized relationships between a category and its concepts and between discrete categories. As the main goal of the analysis was to categorize managerial skills learned and unlearned, the focus was on concepts and categories among the three elements.

Table 2 Key features of participating companies and interviewees

\begin{tabular}{lc}
\hline Industry & $\%$ \\
Manufacturing & \\
(electronics (8), machine (5), food (3), automotive (2), & 56.5 \\
chemicals (2), pharmaceuticals (2), commodities (2), others (2)) & \\
& \\
Non manufacturing & \\
$\quad$ (IT/communications (6), transportation (6), construction (4), & 43.5 \\
insurance (2), trading (2)) & \\
& \\
Number of employees & 8.7 \\
< 1000 & 6.3 \\
1000-4999 & 38.2 \\
5000-9999 & 46.8 \\
>9999 & \\
& \\
Age of interviewees & 21.7 \\
50-54 & 52.1 \\
55-59 & 26.2 \\
> 59 & \\
Organizational position of interviewees & 13.2 \\
President & 13.2 \\
Executive Managing Director & 21.1 \\
Managing Director & 52.5 \\
\hline Director & \\
\hline
\end{tabular}

Note: Figures in parentheses indicate numbers of interviewees.

Strauss and Corbin (1998) proposed the following three steps: open coding, axial coding, and selective coding. Open coding is the process through which categories are identified and their properties (characteristics) and dimensions (the range along which general properties of a category vary) are discovered in data. Axial coding is the process by which categories are systematically developed and related. Selective coding is the process of integrating and refining the theory whereby categories are organized around a central explanatory concept. From among the three steps, the author conducted open and axial coding to extract categories of unlearned managerial skills, and did not use selective coding because the main purpose of this study was to categorize unlearned and learned managerial skills rather than finding central concepts or categories of the skills. Specifically, the author: (1) compared the interview data collected from participants to generate the theoretical properties of the unused or acquired skills (open coding); (2) reduced the list of properties for coding to formulate a smaller and more highly abstract set of 
theoretical properties; and (3) repeated steps (1) to (2) until no new property of the unused or acquired skills emerged (axial coding). Considering the definition of individual unlearning, which assumes the simultaneous occurrence of relinquishing the use of obsolete knowledge and acquiring new knowledge, the author analyzed the finding that managers unlearned some skills when they adopted new skills or ways of thinking. The analysis generated the following three categories: decision making, delegation and motivation, and collecting information.

To supplement the analysis of grounded theory approach, content analysis was conducted to examine the extent to which the three categories were referred to in the interviews. That is, coding in content analysis was conducted after finishing the analysis using the grounded theory approach. Following the standard procedure (Babbie, 2001), two coders (doctoral students) who did not know the purpose of the study were asked to check whether interviewees had any comments on the unlearning of three managerial skills (decision making, delegation and motivation, and collecting information) using 0 (no comment) or 1 (comment). If coders did not agree on coding, they discussed the issue to decide the coding. The coding agreement was $81.7 \%$, which is above the agreement criterion of 0.70 (Lombard et al., 2002).

\section{Results}

The results of the analysis showed that when promoted from senior business manager to executive officer, the participants' knowledge and skills changed, with $87.0 \%$ of the managers experiencing 'unlearning'. These findings are summarized in Table 3. For the three categories, the managerial skills most referred to were 'decision making' (61.5\%), 'delegation and motivation' (59.0\%), and 'collecting information' (35.9\%). These figures refer to the percentage of utterances that executive officers made on related managerial skills or capabilities. Some of the comments made by the officers are paraphrased below. As suggested earlier, unlearning occurs simultaneously with learning. That is, managers unlearn their knowledge and skills when they acknowledge that these are no longer valid or useful and they need to acquire new ones.

\section{Decision making}

Decision making is a skill concerned with managerial judgment and the ways decisions are made. With stakeholders, such as stockholders and analysts, some officers stressed the importance of having management principles:

After becoming a director, I was in the position of having to listen to the opinions of stockholders and analysts, etc., directly. Also, I have to undertake the responsibility of decision making from new perspectives that differ from those of the past, such as taking into consideration dividend levels. In order to deal with these new tasks, it is imperative to possess a knowledge of principles with regard to management and operations, and always to be consistent.

This comment indicates that the manager stopped using internally concentrated decision making skills in learning to make decisions from broader viewpoints, based on management principles. Another officer also pointed out the importance of having a broad perspective in taking a long-term, versus a short-term, view, and in dealing with customers and competitors:

Nowadays I have to think not only of today and tomorrow but also of the 'future', from a long- 
term perspective, when I act. Compared to my former position, as a senior manager, now I am required to have a broader perspective in order to consider matters such as customers, competitors, and technology, in the context of domestic and global markets.

Table 3 Unlearned and learned managerial skills following promotion to executive officer

\begin{tabular}{|c|c|c|c|c|c|}
\hline \multirow{2}{*}{\multicolumn{2}{|c|}{ Categories }} & \multicolumn{2}{|c|}{ Unlearned managerial skills } & \multicolumn{2}{|c|}{ Learned managerial skills } \\
\hline & & Characteristics & Examples & Characteristics & Examples \\
\hline $\begin{array}{l}\text { Decision- } \\
\text { making }\end{array}$ & $61.5 \%$ & $\begin{array}{l}\text { Short-term } \\
\text { Analytic } \\
\text { Partial }\end{array}$ & $\begin{array}{l}\text { Thinking of today and } \\
\text { tomorrow / Using in-depth } \\
\text { analysis and quantified } \\
\text { indicators /Micro } \\
\text { organizational focus /macro } \\
\text { interests for the entire } \\
\text { corporation }\end{array}$ & $\begin{array}{l}\text { Long-term } \\
\text { Intuitive } \\
\text { Holistic }\end{array}$ & $\begin{array}{l}\text { Thinking of the future / Having } \\
\text { a broader perspective /Relying } \\
\text { on intuition in leadership / } \\
\text { Possessing a knowledge of } \\
\text { principles with regard to } \\
\text { management and operations }\end{array}$ \\
\hline $\begin{array}{l}\text { Delegation } \\
\text { and } \\
\text { motivation }\end{array}$ & $59.0 \%$ & Directive & $\begin{array}{l}\text { Being recognized as the top } \\
\text { person / Deciding direction and } \\
\text { directing implementation / } \\
\text { Keeping track of what is } \\
\text { happening }\end{array}$ & $\begin{array}{l}\text { Dedicated } \\
\text { Entrusting }\end{array}$ & $\begin{array}{l}\text { Ensuring everything goes } \\
\text { smoothly even when I am away } \\
\text { / Fostering the people who } \\
\text { require minimum supervision / } \\
\text { Give authority to my } \\
\text { subordinate managers }\end{array}$ \\
\hline $\begin{array}{l}\text { Collecting } \\
\text { information }\end{array}$ & $35.9 \%$ & $\begin{array}{c}\text { Direct } \\
\text { collection }\end{array}$ & $\begin{array}{l}\text { Expecting information from the } \\
\text { operational level / Collecting } \\
\text { workplace information directly }\end{array}$ & $\begin{array}{l}\text { Network-based } \\
\text { collection }\end{array}$ & $\begin{array}{l}\text { Designating a key person at } \\
\text { each division for collecting } \\
\text { information / Enhancing my } \\
\text { network of 'brains' inside } \\
\text { and outside the organization }\end{array}$ \\
\hline
\end{tabular}

There were also officers who, after their promotions, shifted from analytical to intuitive decision making. For example:

When I was a senior manager, my management style was based on in-depth analysis and quantified indicators for all levels, from individuals to customers, as well as business concerns. By doing so, my decisions were more convincing to those around me and, thus, consensus was smoothly established. However, now I am an executive officer, I think it is important to rely heavily on my intuition in my leadership, and to be fluent with regard to a descendent hierarchic approach.

This remark illustrates that he stopped using analytical decision making skills that were based on quantitative data in favor of acquiring intuitive and top-down decision making skills. Another officer explained the importance of change: from thinking about what is most beneficial to the individual unit, to what is most beneficial for the entire organization:

When I was in operational management, it was natural for me to devote myself only to my department and staff, including getting involved in personnel issues like promotions, and securing the maximum budget for my department. If I had not done so, I would not have been able to win my subordinates' trust. However, now I am in corporate management, I have to set aside any 'micro' organizational focus, and act in the best 'macro' interests for the entire corporation. 
These comments suggest that executive officers unlearned the decision making approach of their operational management years, and learned a new approach appropriate to corporate management. Specifically, 'micro' organizational focus refers to short term, analytical concerns, and concentrating on what was best for their business unit, while 'macro' interests indicate longterm, intuitive concerns, and being focused on what is best for the entire company.

\section{Delegation and motivation}

Although it is always necessary for managers to delegate to staff, in contrast to a senior operational manager of a division or a single business unit, an executive officer has control over multiple aspects and is required to manage more indirectly. One officer explained this as follows:

In my experience, what has been most fulfilling about working in an organization is to be given responsibility and authority for an area, to accumulate knowledge and experience of it, and to be recognized as the top person. However, as the breadth of my responsibility widens and the number of my staff increases, I can no longer stay in my comfort zone. Rather, I need to give up such a mentality. This is because the expectations from the organization have changed: I have to transform myself into one of the corporate leaders, not remain as operational staff. In other words, my responsibility has come to mean thinking about how to build teams, while providing my staff with the feeling of satisfaction. Some people may find such responsibility difficult.

This comment suggests that after being promoted to executive officer, the individual needs to undertake a transition from the operational management perspective to the corporate management perspective. The manager seems to have discarded a mentality in which he becomes a hero, and has learned, instead, to make subordinates the main characters. In the same vein, another officer made the following comment:

Retaining the 'direct chain of command' style for defining issues, deciding direction, and directing implementation, is practically impossible; and I think it may further harm the initiative of senior managers. As information and opinions from operational managers and below can only be obtained from the workplace, problems may emerge with regard to how the reception of ideas can remain consistent.

In the comments, the 'direct chain of command' indicates directive management style in which managers tells subordinate staff what they are expected to do and how to perform the expected tasks. His remarks indicate that he gave up the directive management style, and adopted an entrusting and dedicated style, emphasizing delegation. How do executive officers deal with delegation on a larger scale? One officer made this comment:

It is important to ensure everything goes smoothly even when I am away. In order to make it possible, I share my ideas and discuss issues with my subordinates. That way, they have the same sense of approach to the decision making criteria when something comes up unexpectedly. Thus, I can empower them with confidence, and they can play things 'by ear', and make appropriate judgments. This is also beneficial for fostering the people who require minimum supervision. 
This is a good example of how executive managers empower subordinates by sharing decision making criteria. The officer's comment below stressed the importance of clearly interpreting the different policies at operational and corporate levels.

After I became an executive officer, the range of my departmental responsibilities expanded and my previously valuable expertise became useless. When my area of responsibility expands, I am no longer able to keep track of what is happening at the operational level. As a result, there is always a delay in acquiring information from such a level. Without a choice in the matter, I have to give authority to my subordinate managers and, as for myself, business plans must be conducted in a descendent hierarchic approach; each business line works on its own as long as it is on the right track. As per the descendent hierarchic approach, the vision and strategies of the entire organization and its head office have become a 'bible'. However, I can't always be in the dark about the operational level. So, I take the initiative and observe operational staff meetings so that I have a better vision for the status review.

In this comment, the descendent hierarchic approach refers to a top-down management style in which the process of decision making and goal setting is kept at the senior level. These comments suggest that executive officers unlearn the management style acquired during their years as senior operational managers, when they were the lead characters and directed implementation, and have shifted to an entrusting management style in which they make their staff the lead characters while ensuring that decision making criteria are shared, and exert control via the business plan.

\section{Collecting information}

The third category, collecting information, is closely related to delegation, discussed above. As executive officers find themselves detached from operations, and it is more difficult to acquire time-line information, they have to devise other ways of collecting such information. One officer made the following observation:

I think that the higher the position I am in, the more I should stop expecting information. I think it is inappropriate to get frustrated if information doesn't reach me, and I have begun to think it is natural. Executive officers often expect information from the operational level, but the closer we get to the operational level, we find that information is mostly in the form of 'requests'. However, the requests differ from department to department, so it is imperative to amalgamate all these requests and tackle them as issues.

'Request' means a demand from the subordinates about solving problems in the workplace. The comments indicate that he gave up expecting precise information from subordinates in making decisions. Instead, he learned to identify management issues based on subordinates' requests. In a different approach, another officer copes with this difficulty by designating a key person directly between the operational level and corporate level:

Because executive officers are isolated, it is always difficult for information to reach them. Therefore, a key person should be designated at each division for collecting information. 
The term 'isolated' refers to a situation in which there are few people to consult with when in trouble. This manager unlearned the direct approach of collecting information, while he learned to gather information through networks in the organization. In the following comment, which also relates to management decision making, an officer says he makes it a point to have mentors inside and outside of the company, serving as his 'brains':

After I became an executive officer, the range of issues where I make decisions based on my experience has become limited. I frequently encounter cases where I am prompted to use foresight to make decisions proactively. Such experience encourages me to learn more in areas that I am unfamiliar with, and to enhance my network of 'brains' inside and outside the organization.

These comments suggest that executive officers have to unlearn their methods of directly collecting information from the operation, and devise other effective and efficient ways for this that complement their positions; for example, by designating key persons for transmitting information from the operational level and by building a network of mentors inside and outside the company. Although executive officers may face difficulties obtaining information directly from the units they handle, opportunities to acquire information from other units or the external environment may increase.

\section{Discussion}

Executive officers are known to have an impact on unlearning at the organizational level (Hutzschenreuter et al., 2012); however, few studies have investigated the individual unlearning process (Becker, 2005, 2010; Hislop et al., 2014). In particular, an important research issue is to investigate management transitions in the upper echelons of an organization (Hambrick and Mason, 1984; Hambrick, 2007). The findings of this study suggest that executive officers unlearned the managerial skills of 'decision making', 'delegation and motivation', and 'collecting information' in a discontinuous manner. The main contribution of the present research is to demonstrate the discontinuous nature of management transitions from an unlearning perspective.

\section{Theoretical implications}

This study makes two theoretical contributions to the literature on unlearning and managerial skills. First, a major contribution was to extend the existing literature by identifying the types of managerial skills that upper echelon managers should unlearn. As shown in Figure 1, newly promoted executive managers have to substantially transform their skills in 'decision making', 'delegation and motivation', and 'collecting information', corresponding to Mintzberg's (1973) model of managerial roles: decisional, interpersonal, and informational, although these two models are not identical. These results suggest that Mintzberg's (1973) model is useful for explaining the managerial transitions of managers in the upper echelon. This may be because informational roles, which Katz's (1955) managerial skill model and Adner and Helfat's (2003) dynamic capability model do not clearly include, are significant for executive officers in making decisions. The findings suggest that researchers in organizational behavior should be aware of the importance of a manager's information-related capabilities in theorizing managerial skills.

Second, this study contributes to the literature on unlearning and managerial skills by showing 
discontinuous transitions in managerial skills before and after promotions to executive positions. Although the pipeline model (e.g., Charan et al., 2001) and other related research (e.g., Kaiser and Craig, 2011) assume that there is discontinuous management transition when promoting senior managers to executive officers, the findings have tended to be partial, fragmented, or not empirical. As shown in Figure 1, decision making skills were changed from 'short-term, analytic, and partial' to 'long-term, intuitive, and holistic'. Skills in delegation and motivation were transformed from 'directive' to 'dedicated and entrusting'. Skills in collecting information were changed from 'direct collection' to 'network-based collection'. This may be due to task traits of executive officers who have to handle multiple businesses with bigger decisions, and greater risks and uncertainties (Charan et al., 2001). The unlearning of 'decision making' (61.5\%) and 'delegation and motivation' (59.0\%) were more substantial than that of 'collecting information' $(35.9 \%)$. The results suggest that unlearning by executive officers may influence the nature of organizational visions or objectives, which guide and direct employees' behaviors and performance. Although some reports on dynamic managerial capabilities have stressed the importance of cognitive capabilities for executive officers (e.g., Helfeat and Peteraf, 2015), the present research also indicates that they have to unlearn not only cognitive or decision making skills but also human or interpersonal skills.

Senior manager

Decision-
making

Delegation and motivation Collecting
information
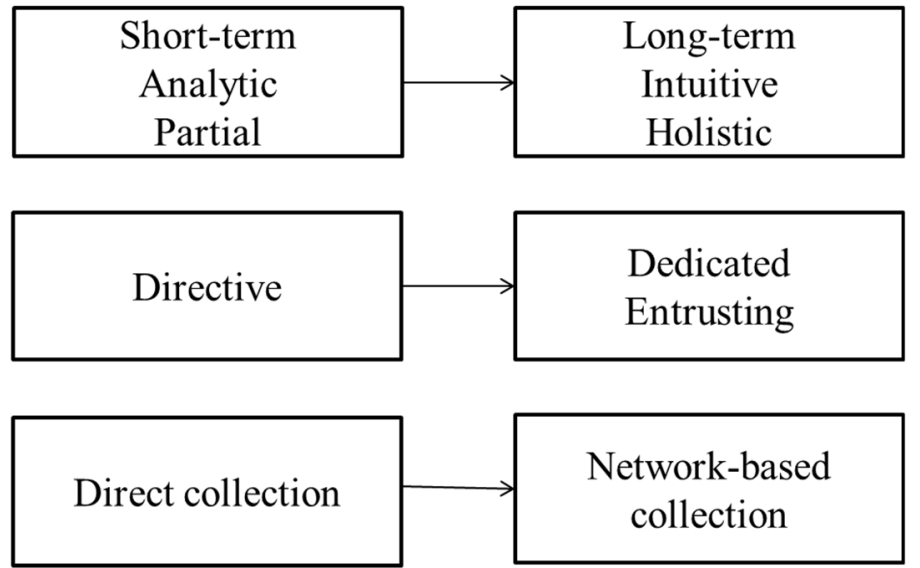

Figure 1 Summary of findings

\section{Practical implications}

This study has implications for management development. First, managers who become executive officers should review all aspects of their managerial skills, including 'decision making', 'delegation and motivation', and 'collecting information', rather than considering only partial improvement. Specifically, executive officers are required to have long-term, intuitive, and holistic viewpoints, to empower subordinates, and to collect information through inside and outside networks. To promote the managerial transition, it may be useful to provide candidates for executive officers with training programs that help them prepare for unlearning obsolete skills and learning necessary ones after they are promoted to executive positions.

Second, managers should note that the changing skill requirement is discontinuous. It is 
ineffective for executive officers to stick with managerial skills that have worked well in the previous position, such as short-term and partial decision making, directive leadership, and direct collection of information. These skills may hinder performance and staff development in the unit. After being promoted to executive positions, managers need feedback on their leadership styles from subordinates, superiors, and colleagues to improve their leadership performance. In addition, executive coaching by external professional coaches or an apprenticeship within top management teams is necessary to improve managerial skills when managers fail to deal with discontinuities in transitions.

Third, HRM departments should introduce several systems and practices to make managers at all levels aware of discontinuities in managerial transitions and the need for unlearning their managerial skills when they are promoted to higher positions. It may be desirable for managers to acquire unlearning capabilities when they are lower or middle managers. To facilitate this, HRM departments need to introduce not only formal systems such as 360-degree appraisals and management training programs but also informal systems including apprenticeships and mentor networks in which senior managers coach their junior managers.

\section{Limitations and future research}

The limitations of this study should be acknowledged. First, the present research focused only on individual unlearning of executive officers, but did not examine the effects of their behaviors on the organization as a whole. To clarify the linkage of individual unlearning with organizational unlearning, future research should investigate how executive officers' unlearning influences organization level unlearning using qualitative and quantitative studies. Additionally, further research is needed to develop a maturity model to explain how managers at each stage in the leadership pipeline model unlearn within an organization.

Second, it is possible that some executive managers had already learned necessary managerial skills when they were senior managers, and that they activated or decided to use the skills after being promoted. In this study, most managers interviewed reported that they acquired new skills after promotion to executive positions, but in rare cases, there must be executive officers who obtained and used 'long-term, intuitive, and holistic' managerial skills at the level of middle managers. It would be an interesting research topic to explore exactly when newly promoted excellent executive officers unlearned and learned.

Third, this study identified the type of management skills unlearned and learned when senior managers were promoted to executive positions, but did not clearly examine the process whereby executive officers unlearned and learned their managerial skills. There must be social situations or events that trigger unlearning. Thus, it is necessary to explore the mechanisms by which managers unlearn and learn skills when promoted from senior managers to executive officers.

Fourth, the data presented in this research are limited to male executive officers in Japanese firms. It is possible that national culture and/or Japanese management styles affected these results. Specifically, it takes more time to be promoted to executive positions in Japan than in other countries. Thus, the findings might not be applicable to Western countries or even to other Asian countries. Although these firms operate in various industries, the sample firms need to be extended to an international context in order to generalize the findings. It would be interesting to replicate similar studies in different contexts.

Finally, interviewers were senior managers who participated in the management training program. It was an advantage that senior managers had good relationships with interviewees, because it allowed them to extract frank opinions in the interviews, but there may have been 
variations in their interview skills. Additionally, this study relied on senior managers as to how they identify the high performing executive officers. There was a possibility that the selection was based on their own personal interests, preferences and prejudices. It is important to choose subjects based on more objective and diversified criteria. Thus, researchers need to select appropriate subjects with the cooperation of HRM departments, and to participate in interviews jointly with senior managers in the future research.

\section{Conclusions}

Organizational unlearning is important in achieving a sustainable competitive advantage. Although executive officers impact organizational outcomes, little is known about unlearning processes in the upper echelon. This study makes an important contribution by identifying discontinuous unlearning flows in managerial skills before and after promotions to executive positions. The present findings suggest that managers need to substantially unlearn their decision making managerial skills as well as delegation and motivation when they are promoted from senior managers to executive officers.

\section{Acknowledgments}

This work was supported by JSPS KAKENHI [grant numbers 26285078].

\section{References}

Adner, R. and C. E. Helfat, 2003, "Corporate effects and dynamic managerial capabilities". Strategic Management Journal, 24: 1011-1025.

Akgun, A. E., J. C. Byrne, G. S. Lynn and H. Keskin, 2007, "Organizational unlearning as changes in beliefs and routines in organizations". Journal of Organizational Change Management, 20: 794-812.

Akgun, A. E., G. S. Lynn and J. C. Byrne, 2006, "Antecedents and consequences of unlearning in new product development teams". Journal of Product Innovation Management, 23: 73-88.

Antal, A. B. and J. Kocka, 2008, "The social science research center Berlin: Organizational learning as a research and institutional project". European Management Review, 5: 55-62.

Babbie, S., 2001, The practice of social research, 9th ed. Belmont, CA: Wadsworth/Thomson Learning.

Becker, K., 2005, "Individual and organizational unlearning: Directions for future research". International Journal of Organizational Behaviour, 9: 659-670.

Becker, K., 2010, "Facilitating unlearning during implementation of new technology". Journal of Organizational Change Management, 23: 251-268.

Cepeda-Carrión, I., A. G. Leal-Millán, J. Ortega-Gutierrez and A. L. Leal-Rodriguez, 2015, "Linking unlearning with service quality through learning processes in the Spanish banking industry". Journal of Business Research, 68: 1450-1457.

Charan, R., S. Drotter and J. Noel, 2001, The leadership pipeline: How to build the leadershippowered company. San Francisco, CA: Jossey-Bass.

Coad, A. and B. Timmermans, 2014, "Two's company: Composition, structure and performance of entrepreneurial pairs". European Management Review, 11: 117-138.

Creswell, J. W., V. L. Plano Clark, M. L. Gutmann and W. E. Hanson, 2003, "Advanced mixed methods research designs". In Tashakkori A. and C. Teddlie (eds.), Handbook of mixed methods in social and behavioral research. Thousand Oaks, CA: Sage, pp. 209-240. 
Dai, G., K. Y. Tang and K. P. De Meuse, 2011, "Leadership competencies across organizational levels: A test of the pipeline model". Journal of Management Development, 30: 366-380.

Dierdorff, E. C., R. S. Rubin and F. P. Morgeson, 2009, "The milieu of managerial work: An integrative framework linking work context to role requirements". Journal of Applied Psychology, 94: 972-988.

Easterby-Smith, M., E. Antonacopoulou, D. Simm and M. Lyles, 2004, "Constructing contributions to organizational learning: Argyris and the next generation". Management Learning, 35: 371-380.

Fernandez, V., J. M. Sallan, P. Simo and M. Enache, 2012, “ Organizational forgetting/unlearning: The dark side of the absorptive capacity". In Hou H. (ed.), New research on knowledge management applications and lessons learned. In Tech: Rijeka, pp. $155-170$.

Freedman, A. M., 2011, "Some implications of validation of the leadership pipeline concept: Guidelines for assisting managers in- transition". Psychologist-Manager Journal, 14: 140159.

Gibbs, B., 1994, "The effects of environment and technology on managerial roles". Journal of Management, 20: 581-604.

Glaser, B. and A. Strauss, 1967, The discovery of grounded theory. Chicago, IL: Aldine.

Haeffner, M., D. Leone, L. Coons and T. Chermack, 2012, "The effects of scenario planning on participant perceptions of learning organization characteristics". Human Resource Development Quarterly, 23: 519-542.

Hambrick, D. C., 2007, "Upper echelons theory: An update". Academy of Management Review, 32: 334-343.

Hambrick, D. C. and P. A. Mason, 1984, "Upper echelons: The organization as a reflection of its top managers". Academy of Management Review, 9: 193-206.

Hedberg, B. L. T., 1981, "How organizations learn and unlearn". In Nystrom P. C. and W. H. Starbuck (eds.), Handbook of organizational design Vol. 1. New York: Oxford University Press, pp. 3-21.

Helfat, C. E. and J. A. Martin, 2015, "Dynamic managerial capabilities: Review and assessment of managerial impact on strategic change". Journal of Management, 41: 1281-1312.

Helfeat, C. E. and M. A. Peteraf, 2015, "Managerial cognitive capabilities and the microfoundations of dynamic capabilities". Strategic Management Journal, 36: 831-850.

Henwood, K. and N. Pidgeon, 1995, "Grounded theory and psychological research". The Psychologist, 8: 115-118.

Hislop, D., S. Bosley, C. R. Coombs and J. Holland, 2014, "The process of individual unlearning: A neglected topic in an under researched field". Management Learning, 45: 540560.

Hsieh, H. and S. E. Shannon, 2005, "Three approaches to qualitative content analysis". Qualitative Health Research, 15: 1277-1288.

Hutzschenreuter, T., I. Kleindienst and C. Greger, 2012, "How new leaders affect strategic change following a succession event: A critical review of the literature". Leadership Quarterly, 23: 729-755.

Johnson, R. B., A. J. Onwuegbuzie and L. A. Turner, 2007, "Toward a definition of mixed methods research". Journal of Mixed Methods Research, 1: 112-133.

Kaiser, R. B., 2011, "The leadership pipeline: Fad, fashion, or empirical fact? An introduction to the special issue". Psychologist-Manager Journal, 14: 71-75. 
Kaiser, R. B. and S. B. Craig, 2011, "Do the behaviors related to managerial effectiveness really change with organizational level? An empirical test". Psychologist-Manager Journal, 14: 92119.

Katz, R. L., 1955, "Skills of an effective administrator". Harvard Business Review, 33: 33-42. Kim, D. H., 1993, "Link between individual and organizational learning". Sloan Management Review, Fall, 37-50.

Klein, J. I., 1989, "Parenthetic learning in organizations: Toward the unlearning of the unlearning model". Journal of Management Studies, 26: 291-308.

Kor, Y. Y. and A. Mesko, 2013, "Dynamic managerial capabilities: Configuration and orchestration of top executives' capabilities and firm's dominant logic". Strategic Management Journal, 34: 233-244.

Lombard, M., J. Snyder-Duch and C. C. Bracken, 2002, "Content analysis in mass communication: Assessment and reporting of intercoder reliability”. Human Communication Research, 28: 587-604.

March, J. G., 1991, "Exploration and exploitation in organizational learning". Organization Science, 2: 71-87.

Martin, J. A., 2011, "Dynamic managerial capabilities and the multibusiness team: The role of episodic teams in executive leadership groups". Organization Science, 22: 118-140.

Martinko, M. J. and W. L. Gardner, 1990, "Structured observation of managerial work: A replication and synthesis". Journal of Management Studies, 27: 329-357.

Meuse, K. P. D., G. Dai and J. Wu, 2011, "Leadership skills across organizational levels: A closer examination". Psychologist-Manager Journal, 14: 120-139.

Mintzberg, H., 1971, "Managerial work: Analysis from observation". Management Science, 18: 97-110.

Mintzberg, H., 1973, The nature of managerial work. New York: Harper Collins Publishers.

Molina-Azorin, J. F., 2012, "Mixed methods research in strategic management: Impact and applications". Organizational Research Methods, 15: 33-56.

Mom, T. J., F. A. J. Van den Bosch and H.W. Volberda, 2007, "Investigating managers' exploration and exploitation activities: The influence of top-down, bottom-up, and horizontal knowledge inflows". Journal of Management Studies, 44: 910-931.

Nystrom, P. C. and W. H. Starbuck, 1984, "To avoid organizational crises, unlearn". Organizational Dynamics, 12: 53-65.

Pavett, C. M. and A. W. Lau, 1983, "Managerial work: The influence of hierarchical level and functional specialty". Academy of Management Journal, 26: 170-177.

Pavett, C. M. and A. W. Lau, 1985, "A comparative analysis of research and development managerial jobs across two sectors". Journal of Management Studies, 22: 69-82.

Rebernik, M. and K. Sirec, 2007, "Fostering innovation by unlearning tacit knowledge". Kybernetes, 36: 406-419.

Rennie, D. L., J. R. Phillips and G. K. Quartaro, 1998, “Grounded theory: A promising approach to conceptualization in psychology?" Canadian Psychology, 29: 139-150.

Sirmon, D. G. and H. A. Hitt, 2009, "Contingencies within dynamic managerial capabilities: interdependent effects of resource investment and development on firm performance". Strategic Management Journal, 30: 1375-1394.

Sosik, J. J., W. A. Gentry and J. U. Chun, 2010, "The value of virtue in the upper echelons: A multisource examination of executive character strengths and performance". Leadership Quarterly, 23: 367-382. 
Starbuck,W.H., 2016, "Organizational learning and unlearning”. Learning Organization, 24: 3038.

Strauss, A. and J. Corbin, 1990, Basics of qualitative research. Newbury Park: Sage.

Strauss, A. and J. Corbin, 1998, Basics of qualitative research, 2nd ed. Newbury Park: Sage.

Teece, D. J., G. Pisano and A. Shuen, 1997, "Dynamic capabilities and strategic management". Strategic Management Journal, 18: 509-534.

Vera, D. and M. Crossan, 2004, "Strategic leadership and organizational learning". Academy of Management Review, 29: 222-240.

Tengblad, S., 2006, "Is there a 'new managerial work': A comparison with Henry Mintzberg's classic study 30 years later". Journal of Management Studies, 43: 1437-1461.

Tsang, E. W. K., 2008, "Transferring knowledge to acquisition joint ventures: An organizational unlearning perspective". Management Learning, 39: 5-20.

Tsang, E. W. K. and S. A. Zahra, 2008, "Organizational unlearning". Human Relations, 61: $1435-1462$.

Zahra, S. A., S. G. Abdelgawad and E. W. K. Tsang, 2011, "Emerging multinationals venturing into developed economies: Implications for learning, unlearning, and entrepreneurial capability". Journal of Management Inquiry, 20: 323-330.

Zhao, Y., Y. Lu and X. Wang, 2013, "Organizational unlearning and organizational relearning: A dynamic process of knowledge management". Journal of Knowledge Management, 17: 902-912. 